\title{
Past and present of active school transportation: An explanation of the influence of the built environment in Toronto, Canada, from 1986 to 2006
}

\author{
Raktim Mitra \\ Ryerson University \\ raktim.mitra@ryerson.ca
}

\author{
Elli M. Papaioannou \\ University of Toronto \\ elli.papaioannou@mail.utoronto.ca
}

\section{Khandker M. Nurul Habib \\ University of Toronto \\ khandker.nurulhabib@utoronto.ca}

\begin{abstract}
The health benefits of walking and cycling to and from school, also called active school transportation (AST), are well documented. In the context of a declining trend in AST across the Western world, this paper examines school-travel behavior of 11-year-old children in Toronto, using multiple cross-sectional data from 1986, 1996, and 2006 Transportation Tomorrow Surveys. Results from binomial logit models suggest that school-travel distance and neighborhood built environment indeed explain some variation in the odds of AST between 1986 and 2006, and that the correlates of AST may have changed over time. Higher neighborhood block density correlated with walking/cycling in 1986. In contrast, household automobile ownership was negatively associated with AST in 2006; the effect of the built environment was relatively weak for that year. In addition, fewer children walked/cycled in 2006 compared to 1986, even when distance to school was short ( $<0.8$ kilometers). Policy and programs should recognize the potentially changing role of travel distance to school and automobile ownership on a child's school travel outcome. Interventions in neighborhoods with high automobile ownership should specifically focus on education and encouragement to increase AST rates.
\end{abstract}

\section{Article history:}

Received: November 25, 2013

Accepted: September 21, 2014

Available online: July 7, 2015

\section{Introduction}

The potential benefits of active school transportation (AST), or walking and cycling to and/or from school, for children and youth are widely recognized. AST provides an opportunity for accumulating physical activity regularly during the school year (Active Healthy Kids Canada 2013; Transportation Research Board 2005; Tudor-Locke, Ainsworth, and Popkin 2001). Those who regularly walk or cycle to and from school also tend to be more independent travelers, and may demonstrate better social and cognitive development compared to children who are regularly driven (Active Healthy Kids Canada

Copyright 2015 Raktim Mitra, Elli M. Papaioannou, and Khandker M. Nurul Habib

http://dx.doi.org/10.5198/jtlu.2015.537

ISSN: 1938-7849 | Licensed under the Creative Commons Attribution - Noncommercial License 3.0

The Journal of Transport and Land Use is the official journal of the World Society for Transport and Land Use (WSTLUR) and is published and sponsored by the University of Minnesota Center for Transportation Studies. This paper is also published with sponsorship from WSTLUR and the Institutes of Transportation Studies at the University of California, Davis, and the University of California, Berkeley. 
2013; Fusco et al. 2012). However, a systematic decline in AST over the past four decades has been reported across Western nations, and the majority of these lost walking or cycling trips were likely replaced by driven trips to and from school (Buliung, Mitra, and Faulkner 2009; McDonald et al. 2011; van der Ploeg et al. 2008; Buliung et al. 2011).

Policymakers, professionals, and grass-roots organizations have taken notice of these low and declining AST rates. Rapid suburbanization and automobile-oriented neighborhood design and decentralization of public schools (i.e., larger and fewer "magnet" schools instead of smaller neighborhood schools) are frequently hypothesized as potential reasons for the decline in walking and cycling among children. In response, several programs have been developed across North America to encourage and enable AST among children and youth attending elementary and middle schools (Buliung et al. 2011; National Center for Safe Routes to School 2007; Green Communities Canada 2013). The neighborhood environment remains a major focus of current initiatives. For example in the United States, significant resources have been dedicated through the federally funded Safe Routes to School (SRTS) programs for improving the built environment near schools (National Center for Safe Routes to School 2007). Canadian School Travel Planning (STP) programs, which are largely community-initiated but publicly funded, also have a major focus on the neighborhood environment (Green Communities Canada 2013).

\section{Current evidence on the correlates of AST}

Recent policy and professional interest around school transportation is backed by an emerging literature that reports important associations between the neighborhood built environment and AST. A detailed discussion of this literature can be found elsewhere (e.g., Mitra 2013; Stewart 2011). In particular, previous research that has explored school travel among students attending elementary and/or middle schools suggests a strong negative association between AST and the distance between home and school locations (Mitra and Buliung 2014; Schlossberg et al. 2006; Yang, Abbott, and Schlossberg 2012). The neighborhoods that are commonly considered "walkable" and safe (e.g., those with small residential blocks, land-use mix, local streets, slow and light traffic, street lights/signs) may encourage walking and/or cycling among children and youth, although empirical findings remain mixed and somewhat inconsistent (Larsen, Gilliland and Hess 2012; McMillan 2007; Mitra and Buliung 2012; Panter et al. 2010a). Perceptions of the neighborhood environment, particularly those related to traffic and personal safety, may also influence school travel outcomes (Lee et al. 2013; Panter et al. 2010b; Timperio et al. 2006).

The importance of socio-demographic characteristics of a child/youth and his or her household on AST uptake is also well documented. Young children (Lee et al. 2013; Mitra, Builiung and Roorda 2010), girls (Larsen et al. 2009; Mitra and Buliung 2012), and those with easy access to private automobiles (Lee et al. 2013; Mitra and Buliung 2014) may be less likely to walk/cycle to school compared to older children/youths, boys, and those with less or no access to private automobiles. Findings related to household/neighborhood income remain mixed (McMillan 2007; Larsen et al. 2009; Mitra and Buliung 2014; Timperio et al. 2006). However, despite a potentially significant influence on travel outcomes, these social aspects have rarely been addressed in current AST-related policy and programs.

Few studies have quantitatively examined the correlates of AST over time. McDonald (2007) found that school-travel distance in the United States has increased considerably between 1969 and 2001, which likely explains a large proportion of the observed decline in AST rates during the same period. By contrast, Grize et al.'s (2010) study of AST trends in Switzerland indicated that cycling rates (adjusted for socio-demographic variations) declined between 1994 and 2005 despite a relatively unchanged school-travel distance over time. In addition, cycling school trips were less likely in "urban" areas in 2000 and 2005, compared to 1994. On the contrary, the socio-demographic correlates of cycling and driving remained similar over time. 


\section{Research questions}

Some exceptions aside, most research into school transportation is cross-sectional. This is a limitation, because while our understanding of the AST behavior continues to emerge, these cross-sectional investigations do not directly explain temporal variation (i.e., decline during the last decades) in AST rates. In particular, the potential changes in the relationship between the built environment and AST over time have yet to be examined empirically. This paper addresses this important gap in current literature particularly by examining the built environment-AST relationship in Toronto, Canada, using multiple cross-sectional survey data. Two research questions were examined in relation to school-travel modechoice behavior in 1986, 1996, and 2006:

- First, do variations in school travel distance and neighborhood built environment explain temporal difference in the odds of undertaking AST?

- Second, have the socio-demographic and built environment correlates of AST remained similar over time?

The latter question is particularly novel in the context of the current trend of declining AST rates. Part of this decline may be explained by a change in parental attitudes toward children's mobility, potentially leading to the current parenting model wherein adult supervision and surveillance are often considered to be essential practices (Fotel and Thomsen 2004; Fyhri et al. 2011; Mitra 2013; Shaw et al. 2013). However, the neighborhood built environment (or rather, the perception of it) may also have contributed to this decline, and this remains the particular focus of our study. Current theoretical works on school-travel behavior have identified neighborhood perceptions (e.g., perceived distance, perceived traffic and personal safety, perceived comfort and attractiveness, perceived opportunity to produce and maintain social capital) as the intervening causal factors that explain the association between physical characteristics of a neighborhood and a child's school travel outcome (McMillan 2005; Mitra 2013). From this theoretical perspective, and in the absence of empirical evidence, two alternative hypotheses can be proposed. First, deterioration of neighborhood environmental qualities, which would produce increased parental concerns about children's safety and their capability of undertaking AST, for example, may explain current school-travel behavior. In this hypothetical scenario, the correlates of AST would remain relatively similar over time. Second, over the past decades, parents may have become more or less sensitive to certain neighborhood environmental characteristics with regard to their children's mobility. A change in these perceptual mediators (i.e., the perceived importance of a built environment metric as an enabler or barrier to walking) over time may produce a difference in the correlation between a built environment metric (e.g., distance, land-use mix) and school travel mode.

If the goal of public policy is to reverse the current trend of declining AST rates, it is critical that the reasons behind this decline are explored, identified, and specifically addressed. This paper advances current research on this topic by improving our understanding of the temporal differences in the sociodemographic and built-environment effects. In addition, the paper provides a Canadian comparison to international case studies (e.g., McDonald 2007; Grize et al. 2010), which is essential for local policy development. The results will help urban planners, health professionals, and grass-roots organizations in designing informed interventions, perhaps within the frameworks of SRTS, STP, or similar programs, to enable walking and cycling among children. 


\section{$4 \quad$ Methods}

\subsection{Study area and data}

School-transportation mode-choice behavior in Toronto, Canada, was examined. Toronto is the largest city in Canada and the fourth largest in North America, and has a population of 2.6 million (Statistics Canada 2012). The neighborhoods in Toronto, which have emerged and grown over the past 200 years, demonstrate large diversity both in terms of the built environment and socio-demographic characteristics of the residents, and provide an appropriate setting for exploring the built environment-AST relationship over time. Similar to other urban regions in the developed world, AST rates in Toronto have declined significantly over the past 25 years. Between 1986 and 2006, for example, the AST rate among 11-to 13-year-old children declined from 57.4 percent to 48.8 percent (Buliung, Mitra, and Faulkner 2009).

The data used in this study come from the Transportation Tomorrow Survey (TTS), which is a series of cross-sectional household travel surveys conducted in the Greater Toronto and Hamilton Area (GTHA) once every five years since 1986 (Data Management Group 2013). For the purpose of this research, data from 1986, 1996, and 2006 surveys were used. Data from the latest TTS (i.e., the 2011 TTS) could not be used because household level travel data was not available to researchers at the time of analysis. The TTS collects retrospective travel-behavior data for a single weekday in fall or spring of each survey year. An adult household member is interviewed over telephone, who proxy-reports for all household members age 11 and older. The 1986 TTS included 4.2 percent sample of all households in the study area. The 1996 and 2006 TTS included 5 percent samples of all households. The survey method was largely consistent across all survey years (Data Management Group 2009).

This study focuses on 11-year-old children's (likely attending grades five or six) home-to-school trips in the morning. Data on younger children were not collected in the TTS. Older children and youth were excluded because most middle schools and high schools in Toronto are located farther apart and are not within easy walking or biking distance for many students. In addition, youths are typically hypothesized as more independent and "mature" travelers compared to children. All school trips that occurred between 6:30 and 9:30 a.m. were explored. This process excluded some trip records from the 1986 TTS data because of missing start time data (Data Management Group 2009).

TTS does not collect data on travel routes, and as a result, true school travel distance could not be included in the analysis. Researchers have explored self-reported (McDonald 2008; McMillan et al. 2007), straight-line (Mitra, Buliung, and Roorda 2010; Yarlagadda and Srinivasan 2008), or network (i.e., minimum path) distance (Mitra and Buliung 2014; Schlossberg et al. 2006; Timperio et al. 2006; Yang, Abbott, and Schlossberg 2012) in absence of travel route data. While most recent studies estimate school-travel distance using a network distance approach, some have questioned the conceptual and empirical validity of this method (Buliung et al. 2013). In this study, straight-line distance between each child's home and school locations was analyzed as a proxy variable representing school-travel distance. Three distance categories were explored: 0 to 0.4 kilometers (i.e., 400 meters is approximately 5 minutes walking distance for a child of this age), 0.4 to 1.6 kilometers (1.6 kilometer or 1 mile approximately represents typical catchment areas for Toronto District School Board), and 1.6 to 3.2 kilometers (a threshold of 3.2 kilometers or 2 miles was assumed to be the maximum feasible walking and cycling distance for a child). All longer trips were excluded from the analysis.

Built-environment characteristics were explored at the scale of traffic analysis zones (TAZ). The TTS divides the city of Toronto into 481 TAZs; each represents a maximum of 3000 people (Data Management Group 2009). Street network characteristics of the TAZs were represented by several variables that were computed using Toronto's 2006 street network file (DMTI CanMap@) RouteLogistics file, 
version 2007.3); GIS street files for the other survey years were not available.

The study analyzed travel behavior data for students living in only 162 out of a total of 481 TAZs. A smaller sample space was considered for two reasons. First, TAZs that did not include at least one recorded school trip in each of the three survey years were excluded from the analysis. The goal was to keep the geographical extent of analysis consistent across time. Second, TAZs that showed visually noticeable changes with regard to street network coverage (i.e., growth or changed layout) during the 1986-2006 time period were excluded to maintain accuracy of the street network related variables, which were measured using the 2006 street network.

Zonal employment-to-population ratio was calculated using the TTS data on work trip ends and residential locations and was explored as a categorical variable $(<0.5,0.5$ to 1.5 , and $>1.5)$ to represent land-use mix within a TAZ. Population and employment densities were also calculated, but these variables were excluded from the final analysis due to multi-collinearity problems. Building age data, obtained from Statistics Canada, was used to identify the maturity of the neighborhoods. This characteristic was explored as a dummy variable that defined a TAZ as new if the majority ( $>50$ percent) of the buildings were less than 15 years old.

Socio-demographic information of a student and his or her household was obtained from TTS (Table 1). Household income data was not collected in TTS. As a result, we supplemented it with zone-based census records of household income and considered the median zonal income to identify low-income neighborhoods.

After reducing the initial sample to include only TAZs with no significant street change and after adjusting for missing data and outliers, the final datasets included 198 home-to-school trips for 1986, 410 trips for 1996, and 427 trips for 2006.

Table 1: Summary statistics (unweighted) for 11-year-old children living within 3.2 kilometers of their schools

\begin{tabular}{|c|c|c|c|c|c|c|}
\hline & \multicolumn{2}{|c|}{$1986(\mathrm{n}=198)$} & \multicolumn{2}{|c|}{$1996(n=410)$} & \multicolumn{2}{|c|}{$2006(n=427)$} \\
\hline & $\%$ & Mean (s.d.) & $\%$ & Mean (s.d.) & $\%$ & Mean (s.d.) \\
\hline \multicolumn{7}{|l|}{ Sex } \\
\hline Female & 51.5 & & 53.2 & & 54.1 & \\
\hline Male & 48.5 & & 46.8 & & 45.9 & \\
\hline Number of children in household & & $1.95(0.78)$ & & $2.13(0.89)$ & & $2.06(0.91)$ \\
\hline Single-adult household & 6.6 & & 12.9 & & 15.5 & \\
\hline All adults in household work full time & 46.0 & & 26.8 & & 29.5 & \\
\hline \multicolumn{7}{|l|}{ Access to personal vehicles } \\
\hline No vehicle & 7.6 & & 17.6 & & 17.6 & \\
\hline One vehicle & 47.5 & & 47.5 & & 52.4 & \\
\hline Two or more vehicles & 44.9 & & 34.9 & & 30.0 & \\
\hline School travel distance $(\mathrm{km})^{a}$ & & $0.75(0.62)$ & & $0.79(0.67)$ & & $0.84(0.66)$ \\
\hline$\leq 0.4 \mathrm{~km}$ & 31.25 & & 33.41 & & 29.04 & \\
\hline 0.4 to $1.6 \mathrm{~km}$ & 58.59 & & 54.15 & & 59.25 & \\
\hline $1.6 \mathrm{~km}$ to $3.2 \mathrm{~km}$ & 10.16 & & 12.44 & & 11.71 & \\
\hline \multicolumn{7}{|l|}{ Travel mode (trip to school) } \\
\hline Walk (active) & 73.3 & & 61.2 & & 56.9 & \\
\hline Cycle (active) & 1.0 & & 0.3 & & 0.5 & \\
\hline Transit (non-active) & 7.5 & & 7.8 & & 6.6 & \\
\hline School bus (non-active) & 10.6 & & 10.7 & & 10.3 & \\
\hline Car (non-active) & 7.6 & & 20.0 & & 25.5 & \\
\hline Other & 0.0 & & 0.0 & & 0.2 & \\
\hline
\end{tabular}

Note: ${ }^{a}$ Mean school travel distance between 1986 and 2006 were not significantly different $(\mathrm{t}=1.66 ; \mathrm{p}=0.10)$. 


\subsection{Analysis}

School travel modes were categorized into active and non-active modes. Active modes include walking or cycling to school, a definition that is consistent with some of the current school transportation literature (e.g., Mitra and Builung 2012a; Panter et al. 2010a; Yang, Abbott, and Schlossberg 2012). Binary logit models were estimated to explore the correlates of active travel to school (versus non-active travel) during the morning period.

Two types of logit models were estimated in this study:

- Models estimated using pooled data from all three survey years. Similar to the method used by Grize et al. (2010), the year of data collection (i.e., 1986, 1996, and 2006) was included in these models as a categorical independent variable. The purpose here was to identify if variations in travel distance and the neighborhood built environment could explain difference in the odds of AST across different temporal points (i.e., the correlation between the year of survey and AST).

- Models estimated using independent datasets for each survey year, and with the same set of independent variables for each year. These models were estimated to explore whether the nature of the relationship between socio-demographic characteristics, the built environment, and AST has remained similar over time.

\section{$5 \quad$ Results}

Among 11-year-old children in Toronto, the proportion of female students ranged between 51.5 percent in 1986 to 54.1 percent in 2006; the difference across the three samples was not statistically significant $\left(\chi^{2}=0.14, d f=2, p=0.93\right)$ (Table 1$)$. The 1986 sample included a lower proportion of single-adult households (although not statistically different from other years) and a higher proportion of households in which all adults worked full time $\left(\chi^{2}=9.62, \mathrm{df}=2, \mathrm{p}=0.018\right)$. The household automobile ownership rate was somewhat different across survey years $\left(\chi^{2}=8.15, \mathrm{df}=4, \mathrm{p}=0.086\right)$. For example in 1986, 45 percent of households had access to two or more privately owned vehicles, compared to only 30 percent of households in 2006. Only TAZs with consistent (over time) street coverage were included in this study. Population density, employment density, and employment-to-population ratio were largely similar across the three survey years. Not surprisingly, however, a lower proportion of neighborhoods in 1986 were "older" neighborhoods (most buildings $>15$ years old), which became more mature by 2006 $\left(\chi^{2}=16.91, \mathrm{df}=2, \mathrm{p}<0.001\right)$.

With regard to travel modes to school, 74.3 percent of all children who lived within 3.2 kilometers ( 2 miles) from school walked or cycled to school in 1986 (Table 1). The rate of using these active modes of travel declined to 57.4 percent by $2006\left(\chi^{2}=6.69, \mathrm{df}=2, \mathrm{p}=0.035\right)$. By contrast, the rate of using non-active modes (i.e., transit, school bus, private automobile, other) for traveling to school increased from 25.8 percent in 1986 to 42.6 percent by 2006.

\subsection{Variations in the built environment and AST}

Table 2 summarizes the results of three binomial logit models of AST, estimated using a pooled sample from all survey years. The difference in the odds of AST between 1986, 1996, and 2006 was examined by first controlling for variations in the socio-demographic characteristics and then by adjusting for variations in travel distance and the neighborhood built environment. The adjusted correlation between survey year and the odds of AST uptake is plotted in Figure 1. Results show that regardless of the variations in socio-demographic characteristics among the three samples, a child was less likely to walk or cycle to school in 1996 and 2006, compared to 1986 (Model 2 in Table 2). In other words, socio- 
demographic variations did not fully explain the trend of a declining likelihood of AST among 11-yearold children (Figure 1). However, when school-travel distance and neighborhood built-environment variables were added to the model, the correlation between survey years and AST was not statistically significant (model 3 in Table 2 and Figure 1), indicating the importance of distance and the neighborhood built environment in understanding quasi-longitudinal variations in AST. However, when school-travel distance and neighborhood built-environment variables were added to the model, the correlation between survey years and AST was not statistically significant (model 3 in Table 2 and Figure 1), indicating the importance of distance and the neighborhood built environment in understanding quasi-longitudinal variations in AST.

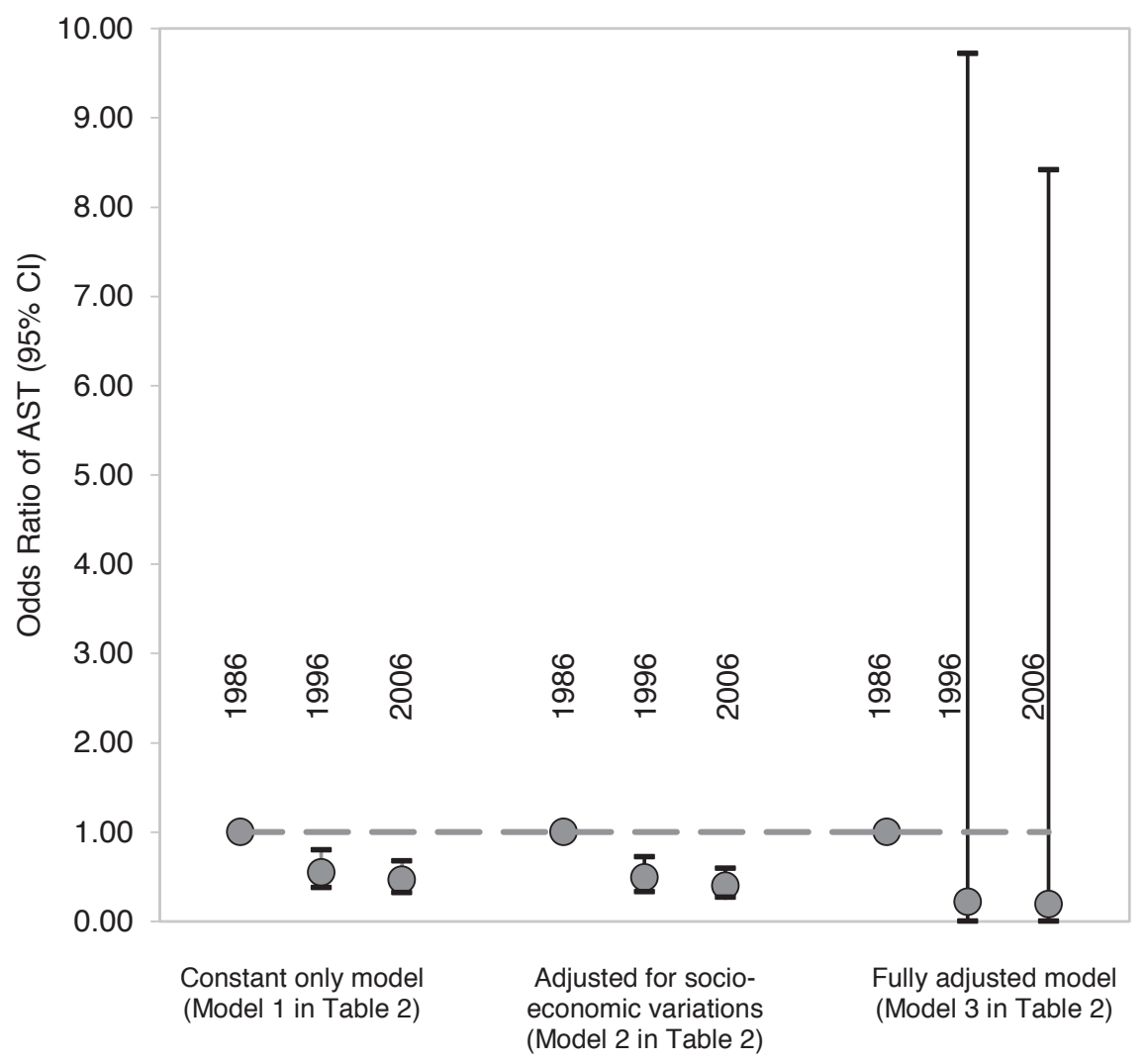

Figure 1: Difference in the correlation between survey year and odds of AST

Note: The correlation between the year of survey and a child's AST uptake is presented in terms of Odds Ratio $\left(\mathrm{OR}=\exp \left(\beta_{i}\right)\right)$ and 95 percent confidence interval brackets; $\mathrm{OR}=1$ represents no statistical association. 
Table 2: Binomial logit model of AST using pooled sample (1986, 1996, and 2006)

\begin{tabular}{|c|c|c|c|c|c|c|}
\hline & \multicolumn{2}{|c|}{$\begin{array}{l}\text { Model } 1 \text { (Constant } \\
\text { only) }\end{array}$} & \multicolumn{2}{|c|}{$\begin{array}{l}\text { Model } 2 \text { (Adjusted for } \\
\text { socio-demographic } \\
\text { variaions) }\end{array}$} & \multicolumn{2}{|c|}{$\begin{array}{l}\text { Model } 3 \text { (Full } \\
\text { adjusted) }\end{array}$} \\
\hline & Coef. (S. E.) & $\mathrm{p}$ & Coef. (S. E.) & $\mathrm{p}$ & Coef. (S. E.) & $\mathrm{p}$ \\
\hline \multicolumn{7}{|l|}{ Survey Year } \\
\hline 1986 & Ref. & - & Ref. & - & Ref. & - \\
\hline 1996 & $-0.59(0.19)$ & 0.00 & $-0.71(0.20)$ & 0.00 & $-1.53(1.80)$ & 0.40 \\
\hline 2006 & $-0.76(0.19)$ & 0.00 & $-0.91(0.20$ & 0.00 & $-1.67(1.80)$ & 0.35 \\
\hline \multicolumn{7}{|l|}{ Sex } \\
\hline Female & & & Ref. & - & Ref. & - \\
\hline Male & & & $0.01(0.13)$ & 0.93 & $-0.02(0.15)$ & 0.91 \\
\hline Number of children in household & & & $0.03(0.08)$ & 0.68 & $-0.06(0.09)$ & 0.50 \\
\hline \multicolumn{7}{|l|}{ Household adults } \\
\hline Multiple adults in household & & & Ref. & - & Ref. & - \\
\hline Single-adult household & & & $-0.12(0.22)$ & 0.59 & $-0.09(0.26)$ & 0.72 \\
\hline \multicolumn{7}{|l|}{ Work force engagement } \\
\hline At least one part-time worker or homemaker & & & Ref. & - & Ref. & - \\
\hline All adults in household work full time & & & $-0.19(0.13)$ & 0.41 & $-0.26(0.17)$ & 0.13 \\
\hline \multicolumn{7}{|l|}{ Access to personal vehicles } \\
\hline No vehicles & & & $0.22(0.21)$ & 0.30 & $0.17(0.24)$ & 0.49 \\
\hline One vehicle & & & Ref. & - & Ref. & - \\
\hline Two or more vehicles & & & $-0.56(0.15)$ & 0.00 & $-0.66(0.18)$ & 0.00 \\
\hline \multicolumn{7}{|l|}{ Neighborhood income } \\
\hline High-income neighborhood (> Median) & & & Ref. & - & Ref. & - \\
\hline Low-income neighborhood (< Median) & & & $0.11(0.13)$ & 0.41 & $0.19(0.16)$ & 0.24 \\
\hline \multicolumn{7}{|l|}{ School-travel distance } \\
\hline$\leq 0.4 \mathrm{~km}$ & & & & & Ref. & - \\
\hline $0.4 \mathrm{~km}$ to $1.6 \mathrm{~km}$ & & & & & $-2.36(0.23)$ & 0.00 \\
\hline $1.6 \mathrm{~km}$ to $3.2 \mathrm{~km}$ & & & & & $-4.43(0.35)$ & 0.00 \\
\hline \multicolumn{7}{|l|}{ Employment/population ratio } \\
\hline Low $(<0.5)$ & & & & & Ref. & - \\
\hline Medium (0.5 to 1.5$)$ & & & & & $-0.29(0.30)$ & 0.34 \\
\hline High $(>1.5)$ & & & & & $-0.30(0.90)$ & 0.74 \\
\hline \multicolumn{7}{|l|}{ Neighborhood maturity } \\
\hline Older (most buildings > 15 years old) & & & & & Ref. & - \\
\hline New (most buildings $<15$ years old) & & & & & $0.16(0.39)$ & 0.67 \\
\hline Density of residential blocks (sq km) & & & & & $0.03(0.02)$ & 0.05 \\
\hline Density of four-way intersections (sq km) & & & & & $-0.02(0.02)$ & 0.48 \\
\hline Density of dead ends and cul-de-sacs (sq km) & & & & & $0.02(0.02)$ & 0.20 \\
\hline (Intercept) & $1.05(0.16)$ & 0.00 & $1.29(0.27)$ & 0.00 & $4.03(2.76)$ & 0.14 \\
\hline $\mathrm{N}$ & 1035 & & 1035 & & 1035 & \\
\hline Null deviance: $-2 \mathrm{~L}[0]$ & 1372.3 & & 1372.3 & & 1372.3 & \\
\hline Residual deviance: $-2 \mathrm{~L}[\mathrm{~B}]$ & 1355.2 & & 1329.9 & & 1025.6 & \\
\hline$-2(\mathrm{~L}[0]-\mathrm{L}[\mathrm{B}])$ & 17.1 & & 42.4 & & 346.7 & \\
\hline McFadden $\rho^{2}$ (adjusted) & 0.02 & & 0.05 & & 0.28 & \\
\hline
\end{tabular}

Note: Coefficients in bold are significant at $\alpha=0.05$; coefficients in bold italics are significant at $\alpha=0.10$.

All neighborhood level variables were measured for the TAZs. 


\subsection{Distance to school and AST}

The potential effect of travel distance on AST was further explored in Figure 2, which plots the proportion of active versus non-active school trips by distance. For short travel distances, more children were walking or cycling in 1986 compared to 1996 or 2006. For example, 87 percent of all children who lived within 800 meters $(0.5$ miles) of school actively traveled to school in 1986. By 2006, this proportion had dropped to only 65 percent. In addition in 1986, the rate of walking or cycling to school was higher than the non-active modes up to a distance of 1.2 kilometers. By 1996, more children were traveling by non-active modes (compared to those who walking or cycled to school) at a distance of 1.2 kilometers; the trend remained similar in 2006.

\subsection{Correlates of AST across three survey years}

To further examine the nature of the relationship between travel distance, the built environment and AST, and potential changes in this relationship over time, separate models of AST were estimated using data from each of the three survey years. Results presented in Table 3 confirm the aggregated analysis shown above by indicating that travel distance consistently correlated with school travel mode choice in 1986, 1996, and 2006. However, these results also indicate that associations between various socio-demographic and built-environment characteristics and AST were different across the three survey years. In 1986, children living in neighborhoods with smaller residential blocks were more likely to walk or cycle to school, and children living in neighborhoods with a higher density of four-way intersections were less likely to travel actively $(\mathrm{p}=0.08)$. None of the socio-demographic characteristics were associated with school travel mode choice in 1986. By contrast, in 1996 and 2006, household automobile ownership was negatively associated with AST (Table 3). Among the built environment characteristics explored in this 2006 model, only one (population-to-employment ratio) showed a weak association $(\mathrm{p}=0.09)$ with AST; the other built-environment variables were not correlated with the odds of walking/cycling. 

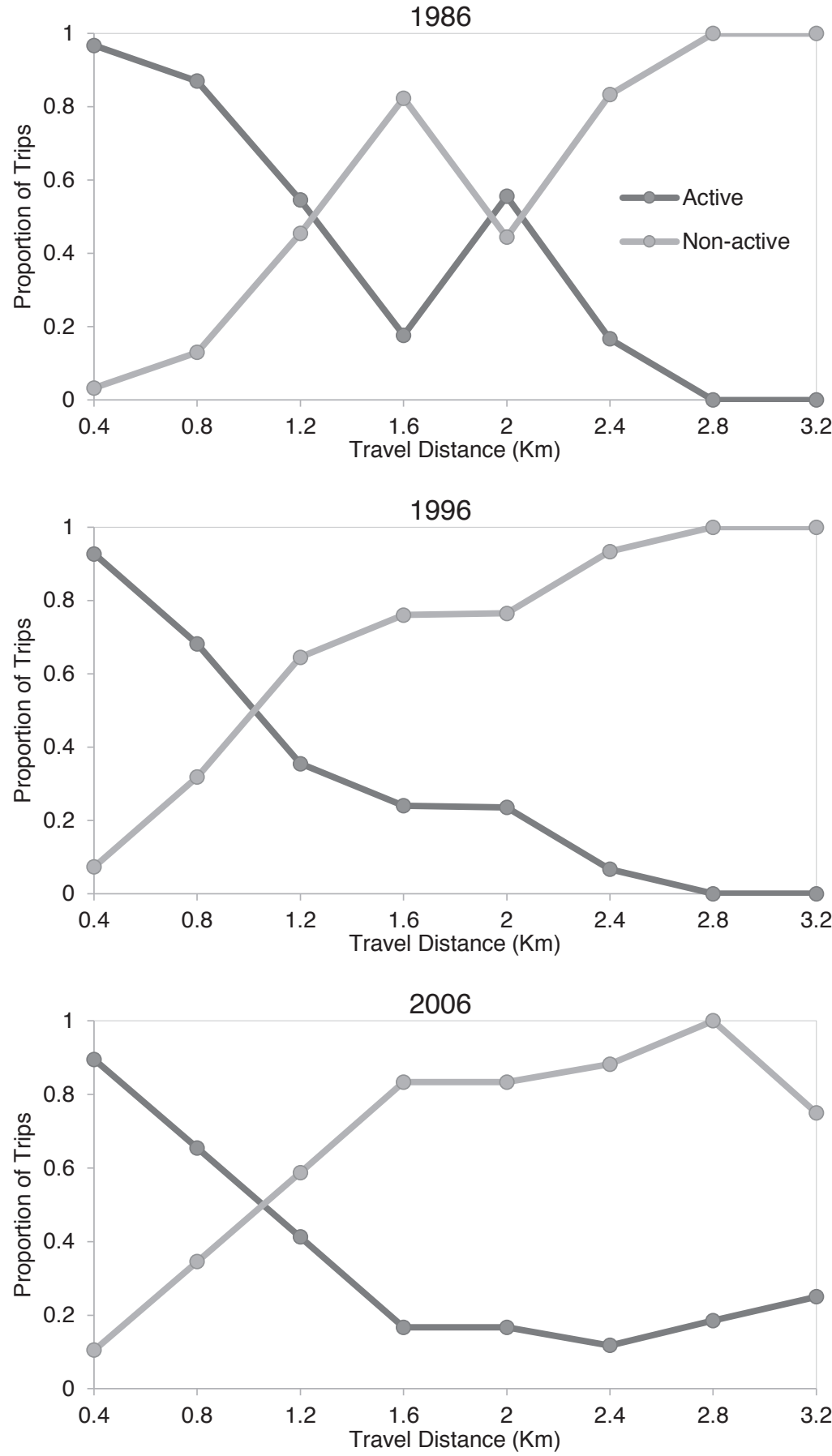

Figure 2: Active and non-active travel modes by distance 
Table 3: Binomial logit model of AST, for 1986, 1996, and 2006

\begin{tabular}{|c|c|c|c|c|c|c|}
\hline & \multicolumn{2}{|l|}{1986} & \multicolumn{2}{|l|}{1996} & \multicolumn{2}{|l|}{2006} \\
\hline & Coef. (S. E.) & $\mathrm{p}$ & Coef. (S. E.) & $\mathrm{p}$ & Coef. (S. E.) & $\mathrm{p}$ \\
\hline \multicolumn{7}{|l|}{ Sex } \\
\hline Female & Ref. & - & Ref. & - & Ref. & - \\
\hline Male & $0.65(0.40)$ & 0.11 & $-0.38(0.26)$ & 0.15 & $0.02(0.24)$ & 0.94 \\
\hline Number of children in household & $0.04(0.26)$ & 0.89 & $-0.25(0.15)$ & 0.09 & $0.13(0.14)$ & 0.35 \\
\hline \multicolumn{7}{|l|}{ Household adults } \\
\hline Multiple adults in household & Ref. & - & Ref. & - & Ref. & - \\
\hline Single-adult household & $-0.12(0.98)$ & 0.90 & $-0.49(0.42)$ & 0.25 & $-0.02(0.39)$ & 0.97 \\
\hline \multicolumn{7}{|l|}{ Work force engagement } \\
\hline At least on part-time worker or homemaker & Ref. & - & Ref. & - & Ref. & - \\
\hline All adults in household work full time & $-0.02(0.41)$ & 0.96 & $-0.38(0.29)$ & 0.20 & $-0.43(0.27)$ & 0.16 \\
\hline \multicolumn{7}{|l|}{ Access to personal vehicles } \\
\hline No vehicles & $0.13(0.82)$ & 0.87 & $0.35(0.39)$ & 0.38 & $-0.01(0.37)$ & 0.98 \\
\hline One vehicle & Ref. & - & Ref. & - & Ref. & - \\
\hline Two or more vehicles & $-0.50(0.42)$ & 0.24 & $-0.58(0.31)$ & 0.06 & $-0.75(0.28)$ & 0.01 \\
\hline \multicolumn{7}{|l|}{ Neighborhood income } \\
\hline High-income neighborhood (> Median) & Ref. & - & Ref. & - & Ref. & - \\
\hline Low-income neighborhood (< Median) & $-0.00(0.00)$ & 0.96 & $-0.00(0.00)$ & 0.30 & $0.41(0.25)$ & 0.10 \\
\hline \multicolumn{7}{|l|}{ School-travel distance } \\
\hline$\leq 0.4 \mathrm{~km}$ & Ref. & - & Ref. & - & Ref. & - \\
\hline $0.4 \mathrm{~km}$ to $1.6 \mathrm{~km}$ & $-2.56(0.77)$ & 0.00 & $-2.49(0.37)$ & 0.00 & $-2.22(0.28)$ & 0.00 \\
\hline $1.6 \mathrm{~km}$ to $3.2 \mathrm{~km}$ & $-4.43(0.92)$ & 0.00 & $-5.02(0.61)$ & 0.00 & $-3.92(0.51)$ & 0.00 \\
\hline \multicolumn{7}{|l|}{ Employment/population ratio } \\
\hline Low $(<0.5)$ & Ref. & - & Ref. & - & Ref. & - \\
\hline Medium (0.5 to 1.5$)$ & $-0.48(0.65)$ & 0.46 & $0.07(0.66)$ & 0.28 & $-0.93(0.49)$ & 0.09 \\
\hline High $(>1.5)$ & na & na & $0.72(1.27)$ & 0.57 & $-0.84(1.40)$ & 0.55 \\
\hline \multicolumn{7}{|l|}{ Neighborhood maturity } \\
\hline Older (most buildings $>15$ years old) & Ref. & - & Ref. & - & Ref. & - \\
\hline New (most buildings $<15$ years old) & $0.18(0.57)$ & 0.75 & $-15.20(590.10)$ & 0.98 & $1.15(0.92)$ & 0.21 \\
\hline Density of residential blocks (sq km) & $0.07(0.03)$ & 0.04 & $0.01(0.02)$ & 0.81 & $0.03(0.02)$ & 0.23 \\
\hline Density of four-way intersections (sq km) & $-0.10(0.05)$ & 0.08 & $0.04(0.04)$ & 0.27 & $-0.02(0.04)$ & 0.54 \\
\hline Density of dead ends and cul-de-sacs (sq km) & $0.00(0.04)$ & 0.94 & $0.01(0.03)$ & 0.65 & $0.04(0.03)$ & 0.17 \\
\hline (Intercept) & $2.70(1.44)$ & 0.06 & $3.46(0.83)$ & 0.00 & $1.19(0.58)$ & 0.04 \\
\hline $\mathrm{N}$ & 198 & & 410 & & 427 & \\
\hline Null deviance: $-2 \mathrm{~L}[0]$ & 225.92 & & 546.64 & & 582.62 & \\
\hline Residual deviance: $-2 \mathrm{~L}[\mathrm{~B}]$ & 172.86 & & 376.19 & & 430.82 & \\
\hline$-2(\mathrm{~L}[0]-\mathrm{L}[\mathrm{B}])$ & 39.86 & & 170.45 & & 151.80 & \\
\hline McFadden $\rho^{2}$ (adjusted) & 0.30 & & 0.34 & & 0.28 & \\
\hline
\end{tabular}

Note: Coefficients in bold are significant at $\alpha=0.05$; coefficients in bold italics are significant at $\alpha=0.10$.

All neighborhood level variables were measured for the TAZs. 


\section{Discussion}

In the context of a limited understanding of how school-travel behavior might have changed over the past decades (Grize et al. 2010; McDonald 2007), this paper examined walking/cycling for trips to school in Toronto using data from three large cross-sectional surveys conducted in 1986, 1996, and 2006. This paper makes an important contribution by exploring the potential effects of the neighborhood built environment over this 20-year period, a topic that remains understudied in the current literature.

A comparison between the three samples suggests that AST has declined by 22.7 percent between 1986 and 2006 (Table 1). During the same period, the use of other non-active modes of travel, including transit, school bus, and private automobiles, has increased by 65.8 percent. This observation is not unexpected, because a similar trend was reported in previous research conducted in Toronto and in other parts of the Western World (Buliung, Mitra, and Faulkner 2009; Grize et al. 2010; McDonald 2007).

Our paper examined two research questions related to this declining trend in AST. With regard to the first research question, the model results suggest that variations in travel distance and the neighborhood built environment may partially explain declining AST rates. Our second question was informed by current conceptual frameworks of children's school-travel behavior (McMillan 2005; Mitra 2013); we expected to find a difference in the association between the built environment and AST particularly between 1986 and 2006, which might relate to a change in the perception of the built environment as an enabler or barrier to walking or cycling. The model results suggest that the correlates of AST may have changed over the past 20 years. In other words, the association between various socio-demographic and built-environment characteristics and AST was different between the time periods studied (1986, 1996, and 2006).

To elaborate, results from this study suggest that distance to school (or the perception of it) was an important barrier to AST in Toronto for all survey years (Table 3) and had the largest contribution to model fit across all survey years. This observation is similar to what has been reported for school trips in the United States (McDonald 2007). McDonald concluded that half of the decline in the walking rate between 1977 and 2001 in the United States can be explained by increased travel distance to school during this period. The Toronto context is different from that in the United States; most children attend public elementary schools that are located within their neighborhoods of residence and a short distance from their homes (Mitra and Buliung (2014). Not surprisingly, then, the mean school travel distance for 11-year-old children in Toronto did not change during the 1986-2006 period (Table 1). However, unlike Grize et al.'s (2010) work that explored school-travel behavior of Swiss children ages 6 to14 and reported that school travel distance did not change over time and did not explain a declining trend in AST rates, our findings indicate an important relationship between travel distance and walking/cycling to school (Table 3 and Figure 2). Particularly important is the finding that more children in Toronto were using non-active modes for short trips to school (i.e. $<0.8$ kilometers or 0.5 miles) in 2006 compared to 1986 (Figure 2). Speculatively, a child's capability (or rather, the perception of it) of undertaking AST may diminish with increased travel distance. Findings from this study may suggest that child or caregiver perceptions regarding a "walkable" travel distance to school have changed, producing a much shorter acceptable distance threshold today than two decades ago.

The neighborhood built environment had an important association with AST uptake in 1986. Smaller residential blocks, the neighborhood design feature that is typical of an inner-city "walkable" neighborhood in Toronto, was correlated with higher odds of walking or cycling to school (odds ratio, $\mathrm{OR}=1.07 ; \mathrm{p}=0.04$ ) (Table 3 ). With regard to children's mobility, a neighborhood with smaller blocks may enable walking and cycling by bringing more "eyes on street" and thus producing a sense of pedestrian safety (McMillan 2007; Mitra 2013). Similarly, a high density of four-way intersections in the TAZ 
of residence, which is typically representative of a higher concentration of busy roads with faster traffic, reduced the odds of AST in 1986 (OR = 0.90; $\mathrm{p}=0.08$ ) (Giles Corti et al. 2011; Mitra and Buliung 2012; Schlossberg et al. 2006). In contrast, the correlation between neighborhood built environment and AST was rather weak in 2006. Our data does not allow us to make conclusive comments about the behavioral difference between 1986 and 2006. However, drawing on the conceptual models of schooltravel behavior (McMillan 2005; Mitra 2013), our speculation is that perceived role of the neighborhood in enhancing or reducing travel safety of a child, may have weakened over time.

An interesting finding also emerged in terms of the socio-demographic correlates of AST. Previous research that has explored the historical trends in travel behavior in the GTHA reported a modest increase in automobile dependence for non-work and school travel in this region over the past decades (Miller and Shalaby 2003; Miller and Soberman 2003). Evidence from our study suggests the same. While in 1986, automobile ownership was uncorrelated with the odds of walking and cycling to school among 11 -year-old children, by 2006 , access to private automobiles likely played an important role in school travel mode choice. Children living in households with two or more cars were significantly less likely to undertake AST (OR = 0.47; p = 0.01) (Table 3). Unlike in 1986, children were more likely to be captive users of active modes of travel (i.e., would walk/cycle only when access to private automobiles was limited) in 2006. No other socio-demographic variable, including a child's sex and median household income of a neighborhood, was statistically associated with AST in any of the three survey years.

This study has some strengths and limitations. First, we did not explore longitudinal data of schooltravel behavior, and the results do not directly explain any "change" in mode-choice behavior. Instead, multiple large cross-sections of data, obtained from comparable population-based surveys undertaken between 1986 and 2006, were examined. The geographic extent of analysis was kept consistent across time (i.e., the sample came from the same TAZs). However, there were some differences in socio-demographic characteristics across the three samples, which might affect comparability. That said, large historical datasets of travel behavior, similar to the ones used in this study, are not available for most urban regions. The results from this study then provide valuable and much-needed insight into the difference in the correlates of AST in Toronto across the three survey years and over a period of 20 years. Our findings may help explain a declining trend in AST during this time.

Second, the scope of analysis was limited to several socio-demographic and neighborhood environmental characteristics. However, a modest model fit (Table 3) indicates the presence of other important influences on travel-mode-choice behavior that remain unobserved in this study. One particularly important unobservable effect is the caregiver/student's attitude toward parental escorting and school travel modes. This potential effect is difficult to explore empirically because of the absence of historical data on travel attitudes and was not addressed in this study.

Lastly, existing research on school transportation has measured built-environment variables at different geographical scales and using different zoning schemes. Studies using census boundaries typically report a weaker association between the built environment and school-travel outcomes (e.g., Ewing, Schroeer, and Greene 2004; Mitra and Buliung 2012; Yarlagadda and Srinivasan 2008). It is possible that the modifiable areal unit problem (Fotheringham and Wond 1991; Mitra and Buliung 2012) could partly explain the weaker built-environmental associations observed in this study. As a result, some caution should be exercised when comparing our results (particularly, those related to the built environment) to findings from other recent studies. However, for each of the three datasets examined in this study, the built-environment characteristics were measured at the TAZ level. In addition, the TAZ boundaries remained consistent during the 1986-2006 period, and we only analyzed data from a TAZ when there was at least one trip record available from that TAZ for each of the three survey years. The results across the three periods, then, are comparable within the context of our study area. 


\section{$7 \quad$ Implications and conclusions}

Findings from this research have important policy implications. Between 1999 and the first decade of the 2000s, more than 200 schools were closed in the province of Ontario, Canada, as part of a provincewide education restructuring policy (Basu 2007). More recently in 2015, the Toronto District School Board (TDSB, the largest public school board in Canada, and fourth largest in North America) announced a list of 48 neighbourhood elementary schools with lower enrollment rates for potential closure within the next 10 years (Toronto District School Board, 2015). A similar trend in the US has been observed in the past several decades, where smaller neighbourhood schools are being closed in favor of large "magnet schools" (Schlossberg et al. 2006; Yang, Abbott and Schlossberg 2012). The school transportation literature has consistently pointed out that such a policy may discourage walking and cycling, because larger schools will draw students from larger areas, increasing the average school travel distance (McDonald 2007; Yang, Abbott and Schlossberg 2012). Our findings are similar to what has been reported previously, and implies that this type of economic rationalization of school locations (leading to closing the doors of neighborhood schools) may have negative implications on the health and well being of the elementary schoolchildren.

Recent years have seen a significant increase in public funding being committed to programs and initiatives focused on both structural (e.g., street design, sidewalks) and non-structural (e.g., walk to school day, walking school bus) interventions that might enable AST. For example, in the United States, $\$ 862$ million in federal government funding has been allocated since 2005 for the implementation of SRTS programs (National Center for Safe Routes to School 2007; Stewart 2011). In Canada, the Public Health Agency of Canada and Transport Canada have supported the implementation of STP initiatives since 2007 (Buliung et al. 2011; Green Communities Canada 2013; Metrolinx 2011). While no longer-term revenue stream has been identified, Metrolinx, the provincial transportation authority for the GTHA, continues to support community mobilization as a way to enable walking, cycling, and transit use for school transportation. However, when designing interventions, urban planners, public health professionals, and community-based organizations need to recognize the potentially changing role of the neighborhood environment in encouraging or restricting walking and cycling among children. Educational interventions, on the contrary, appear to offer some promise in the current context. For example, caregivers and children could be made more aware of the benefits of walking. Parents should be encouraged to allow children to walk or cycle to school particularly when the distance between home and school is reasonably short. Our data suggests that 70 percent of 11 -year-old children in Toronto lived within 1.6 kilometers (1 mile; straight-line distance) of their schools. When distance is short, travel time for a walking/cycling trip to school may not be considerably different compared to a car trip (Black, Collins, and Snell 2001), and AST can be a healthy and environmentally sustainable choice for such trips. Programs and interventions should particularly focus on parents and children who live in neighborhoods with high levels of automobile ownership. Such interventions warrant greater policy attention in addressing and perhaps reversing the current trend of decline in AST, and more broadly, in building more sustainable and healthy communities for children and youth. 


\section{Acknowledgements}

Financial support for this research was provided to the first author from the Faculty of Community Services at Ryerson University. We also wish to thank the Data Management Group of the Urban Transportation Research and Advancement Center at the University of Toronto for allowing us to work with the TTS data.

\section{References}

Active Healthy Kids Canada. 2013. 2013 Active healthy kids Canada report card on physical activity for children and youth. http://www.activehealthykids.ca/2013ReportCard/en/.

Basu, R. 2007. Negotiating acts of citizenship in an era of Neoliberal reform: The game of school closures. International Journal of Urban and Regional Research 31(1):109-127.

Black, C., A. Collins, and M. Snell. 2001. Encouraging walking: The case of journey-to-school trips in compact urban areas. Urban Studies 38(7): 1121-1141.

Buliung, R. N., R. Mitra, and G. E. J. Faulkner. 2009. Active school transportation in the Greater Toronto Area, Canada: An exploration of trends in space and time (1986-2006). Preventive Medicine 48(6): 507-512.

Buliung, R., G. E. J. Faulkner, T. Beesley, and J. Kennedy. 2011. School Travel Planning: Mobilizing school and community resources to encourage active school transportation. Journal of School Health 81(11): 704-712.

Buliung, R., K. Larsen, G. E. J. Faulkner, and M. R. Stone. 2013. The "path" not taken: Exploring structural differences in mapped- versus shortest-network-path school travel routes. American Journal of Public Health 103(9): 1589-1596.

Data Management Group. 2009. Transportation Tomorrow Survey 2006: Data guide version 1.0. University of Toronto. http://www.dmg.utoronto.ca/reports/ttsreports.html.

Data Management Group. 2013. Transportation Tomorrow Survey. University of Toronto. http://www. dmg.utoronto.ca/transportationtomorrowsurvey/.

Ewing, R., W. Schroeer, and W. Greene. 2004. School location and student travel: Analysis of factors affecting mode choice. Transportation Research Record 1895: 55-63.

Fotel, T., and T. U. Thomsen. 2004. The surveillance of children's mobility. Surveillance and Society 1(4): 535-554.

Fotheringham, A. S., and D. W. S. Wong. 1991. The modifiable areal unit problem in multivariate statistical analysis. Environment and Planning A 23(7): 1025-1044.

Fusco, C., F. Moola, G. E. J. Faulkner, R. Buliung, and V. Richichi. 2012. Toward an understanding of children's perceptions of their transport geographies: (Non)active school travel and visual representations of the built environment. Journal of Transport Geography 20(12): 62-70.

Fyhri, A., R. Hjorthol, R. L. Mackett, T. N. Fotel, and M. Kyttä. 2011. Children's active travel and independent mobility in four countries: Development, social contributing trends and measures. Transport Policy 18: 703-710.

Giles-Corti, B., G. Wood, T. Pikora, V. Learnihan, M. Bulsara, K. Van Niel, A. Timperio, G. McCormack, and K. Villanueva. 2011. School site and the potential to walk to school: The impact of street connectivity and street exposure in school neighborhoods. Health and Place 17: 545-550.

Green Communities Canada. 2013. Active and Safe Routes to School. http://www.saferoutestoschool .cal. 
Grize, L., B. Bringolf-Isler, E. Martin, and C. Braun-Fahrlander. 2010. Trend in active transportation to school among Swiss schoolchildren and its associated factors: Three cross-sectional surveys 1994, 2004, and 2005. International Journal of Behavioral Nutrition and Physical Activity 7: 28. http:// www.ijbnpa.org/content/7/1/28.

Larsen, K., J. Gilliland, P. Hess, P. Tucker, J. Irwin, and M. He. 2009. The influence of the physical environment and socio-demographic characteristics on children's mode of travel to and from school. American Journal of Public Health 99(3): 520-526.

Larsen, K., J. Gilliland, and P. M. Hess. 2012. Route-based analysis to capture the environmental influences on a child's mode of travel between home and school. Annals of the Association of American Geographers 102(6): 1348-1365.

Lee, C., X. Zhu, J. Yoon, and J. W. Varni. 2013. Beyond distance: Children's school travel mode choice. Annals of Behavioral Medicine 45(sup 1): S55-S67. doi: 10.1007/s 12160-012-9432-z.

McDonald, N. C. 2007. Active transportation to school: Trends among US schoolchildren, 19692001. American Journal of Preventive Medicine 32(6): 509-516.

McDonald, N. C. 2008. Children's mode choice for the school trip: The role of distance and school location in walking to school. Transportation 35(1): 23-35.

McDonald N. C., A. L. Brown, L. M. Marchetti, and M. S. Pedroso M. 2011. US school travel, 2009: An assessment of trends. American Journal of Preventive Medicine 41(2): 146-151.

McMillan, T. E. 2005. Urban form and a child's trip to school: The current literature and a framework for future research. Journal of Planning Literature 19(4): 440-456.

McMillan, T. E. 2007. The relative influence of urban form on a child's travel mode to school. Transportation Research Part A 41(1): 69-79.

Metrolinx. 2011. Active and Sustainable School Travel. Ontario: Government of Ontario. http://www. metrolinx.com/en/projectsandprograms/schooltravel/school_travel.aspx.

Miller, E., and A. Shalaby. 2003. Evolution of personal travel in Toronto area and policy implications. Journal of Urban Planning and Development 129(1): 1-26.

Miller, E., and R. M. Soberman. 2003. Travel Demand and Urban Form. Issue Paper No. 9. Toronto: NEPTIS Foundation.

Mitra, R., R. Buliung, and M. J. Roorda. 2010. The built environment and school travel mode choice in Toronto, Canada. Transportation Research Record 2156: 2150-2159.

Mitra, R., and R. N. Buliung. 2012a. Built environment correlates of active school transportation: Neighborhood and the modifiable areal unit problem. Journal of Transport Geography 20(12): 51-61.

Mitra, R. 2013. Independent mobility and mode choice for school transportation: A review and framework for future research. Transportation Reviews 33(1): 21-43.

Mitra, R., and R. N. Buliung. 2014. The influence of neighborhood environment and household travel interactions on school travel behavior: An exploration using geographically weighted models. Journal of Transport Geography 36: 69-78.

National Center for Safe Routes to School. 2007. Safe Routes to School Guide. http://www.saferoutesinfo. org/guide/.

Panter, J. R., A. P. Jones, E. M. F. Van Sluijs, and J. Griffin. 2010a. Neighborhood, route, and school environments and children's active commuting. American Journal of Preventive Medicine 38(3): 268278.

Panter, J. R., A. P. Jones, E. M. F. van Sluijs, and S. J. Griffin. 2010b. Attitudes, social support and environmental perceptions as predictors of active commuting in schoolchildren. Journal of Epidemiology and Community Health 64: 41-48.

Schlossberg, M. J., P. Greene, P. Phillips, B. Johnson, and B. Parker. 2006. School trips: Effects of urban 
form and distance on travel mode. Journal of the American Planning Association 72(3): 337-346.

Shaw, B., B. Watson, B. Frauendienst, A. Redecker, T. Jones, and M. Hillman. 2013. Children's Independent Mobility: A Comparative Study in England and Germany (1971-2010). London: Policy Studies Institute. http://www.psi.org.uk/site/publication_detail/852.

Statistics Canada. 2012. Toronto, Ontario (Code 3520) and Ontario (Code 35) (table). Census profile. 2011 Census. Catalogue no. 98-316-XWE. http://www12.statcan.gc.ca/census-recensement/2011/ dp-pd/prof/details/page.cfm?Lang=E\&Geo1=CSD\&Code1=3520005\&Geo2=CD\&Code2=352 $0 \&$ Data $=$ Count $\&$ SearchText $=$ toronto $\&$ Search Type $=$ Begins $\&$ SearchPR $=01 \& B 1=A l l \&$ Custom $=\&$ $\mathrm{TABID}=1$.

Stewart, O. 2011. Findings from research on active transportation to school and implications for Safe Routes to School programs. Journal of Planning Literature 26(2): 127-150.

Timperio, A., K. Ball, J. Salmon, R. Roberts, B. Giles-Corti, D. Simmons, A. L. Baur, and D. Crawford. 2006. Personal, family, social, and environmental correlates of active commuting to school. American Journal of Preventive Medicine 30(1): 45-51.

Toronto District School Board. 2015. Response to the Minister's Directive 9 of the Toronto District School Board, letter dated 15 January 2015 (revised). http://www.tdsb.on.ca/Leadership/Boardroom/AgendaMinutes.aspx?'Type=A\&Folder $=$ Agenda\%2f20150210\&Filename $=150210+$ Minister $\% 27 s+$ Response+Directive+9REVatBRD.pdf.

Transportation Research Board Committee on Physical Activity, Health,Transportation, and Land Use. 2005. Does the Built Environment Influence Physical Activity? Examining the Evidence. Special report no. 282. Washington, DC: Transportation Research Board of the National Academies.

Tudor-Locke, C., B. E., Ainsworth, and B. M. Popkin. 2001. Active commuting to school: An overlooked source of children's physical activity? Sports Medicine 31(5): 309-313.

van der Ploeg, H. P., D. Merom, G. Corpuz, and A. E. Bauman. 2008. Trends in Australian children traveling to school 1971-2003: Burning petrol or carbohydrates? Preventive Medicine 46(1): 60-62.

Yang, Y., S. Abbott, and M. Schlossberg. 2012. The influence of school choice policy on active school commuting: A case study of a middle-sized school district in Oregon. Environment and Planning A 44: 1856-1874.

Yarlagadda, A. K., and S. Srinivasan. 2008. Modeling children's school travel mode and parental escort decisions. Transportation 35(2): 201-218. 